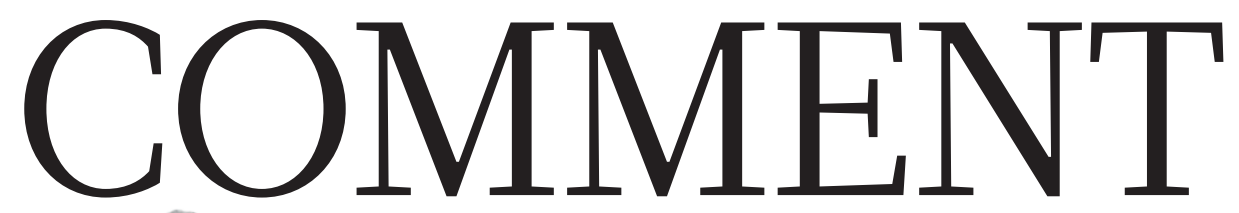

HISTORY William Astbury, another overlooked figure in the DNA-structure story $\mathbf{p . 3 2}$
MEDICINE A chronicle of

shifting attitudes to US childhood obesity $\mathbf{p . 3 4}$
DATA Citizen science from previous centuries is ripe for mining $\mathbf{p . 3 5}$
OBITUARY Gerald Guralnik, Higgs-boson physicist, remembered $\mathbf{p . 3 6}$

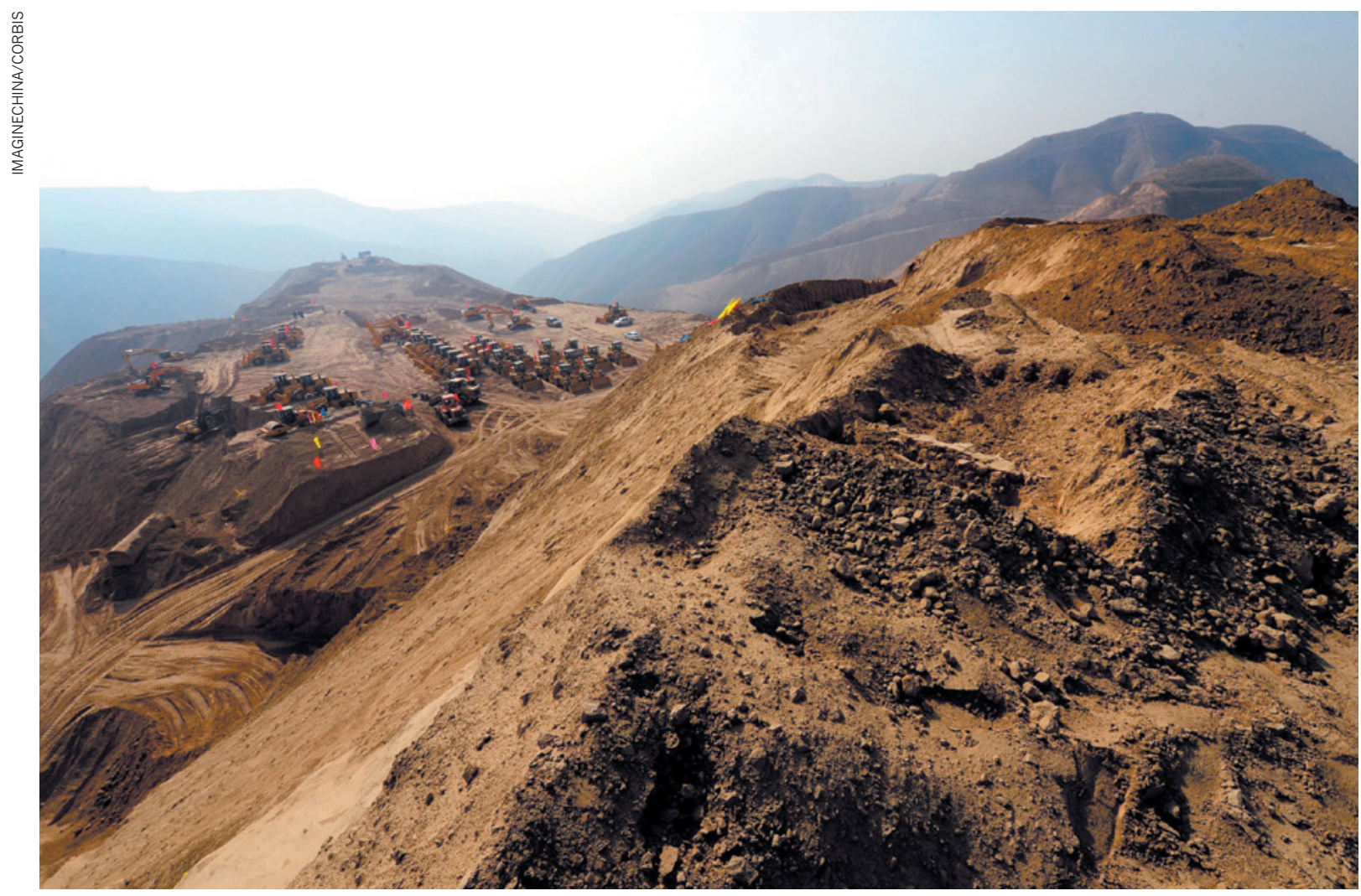

In Lanzhou, China, 700 mountains are being levelled to create more than 250 square kilometres of flat land.

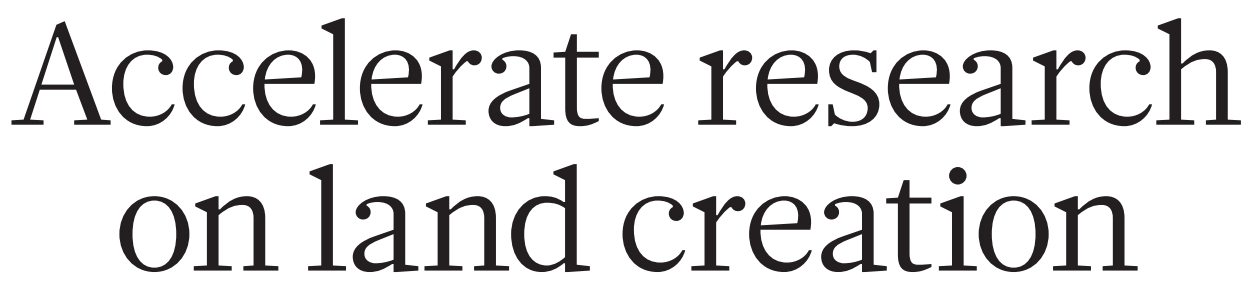

China's campaign to bulldoze mountains to build cities needs expertise to avert geoengineering problems, warn Peiyue Li, Hui Qian and Jianhua Wu.

C hina's cities are expanding rapidly as its economy grows ${ }^{1}$. Yet land for development is in short supply, particularly in mountainous areas, where about one-fifth of the population lives ${ }^{2}$. In the past decade, local governments have begun removing the tops of mountains to fill in valleys to create land on which to build.

This is reminiscent of an ancient Chinese fable, 'The Foolish Old Man who Removed the Mountains'. In the tale, a 90-year-old man convinces his disbelieving neighbour that he can dig away, stone by stone, two mountains that block the way from his house. Because he succeeds (albeit with the help of deities) the fable is often cited - including by Mao Zedong - to illustrate the power of perseverance. But in our view, China should heed the story's title: earth-moving on this scale without scientific support is folly.

In cities such as Chongqing, Shiyan, Yichang, Lanzhou and Yanan, tens of square kilometres of land have been created ${ }^{3}$ (see 'Moving mountains'). One of the largest projects, which started in April 2012 in Yan'an in the Shaanxi province, will double the city's current area by creating 78.5 square kilometres of flat ground ${ }^{3}$. Local officials are optimistic that the sale or leasing of the new land will generate billions of renminbi, while easing pressures on agriculturally or culturally valuable land elsewhere.

But the consequences of these 
unprecedented programmes have not been thought through - environmentally, technically or economically. There has been too little modelling of the costs and benefits of land creation. Inexperience and technical problems delay projects and add costs, and the environmental impacts are not being thoroughly considered. Yan'an, for example, is the largest project ever attempted on loess, thick million-year-old deposits of windblown silt. Such soft soils can subside when wet, causing structural collapse ${ }^{4}$.

Overcoming these problems will require the sharing of experiences and technical strategies nationally and internationally. Collaboration between universities, research institutes, private companies, construction teams and governments is needed to ensure that the best research informs the engineering, so that the vast sums of public money involved are invested wisely. Without cooperation, the land-creation campaigns could drain local and national economies and irrevocably damage watercourses and ecosystems.

\section{TOO LITTLE, TOO LATE}

Land creation by cutting off hilltops and moving massive quantities of dirt is like performing major surgery on Earth's crust ${ }^{5}$. Mountaintop moving has been done before in strip mining, especially in the eastern United States ${ }^{6,7}$. But it has never been carried out on this scale. In China, dozens of hills 100-150 metres in height are being flattened over hundreds of kilometres. Such infill has never been used for urban construction. There are no guidelines for creating land in the complex geological and hydrogeological conditions that are typical of mountainous zones.

Land-creation projects are already causing air and water pollution, soil erosion and geological hazards such as subsidence", " "Government They destroy forests funds are and farmlands and not allocated. endanger wild ani- according mals and plants. The toscientific city of Shiyan, for significance example, lies near orneed." the headwaters of the

South-North Water Transfer Project - a major initiative to divert water from rivers through canals in southern China to Beijing and the north. There, the changing of hills to plains has caused landslides and flooding, and altered watercourses. This causes greater soil erosion, increasing the sediment content of local water sources (see go.nature.com/ klasxh; in Chinese).

In Yan'an, the air is often brown with dust owing to construction teams working on windy days without dampening the soil. Forests and plants on hills and in gullies are stripped ahead of the demolition and filling.

\section{MOVING MOUNTAINS}

Tens of square kilometres of land have been created by levelling hills in several cities in mainland China. Work began in 2012 to make nearly 80 square kilometres of flat ground in Yan'an.

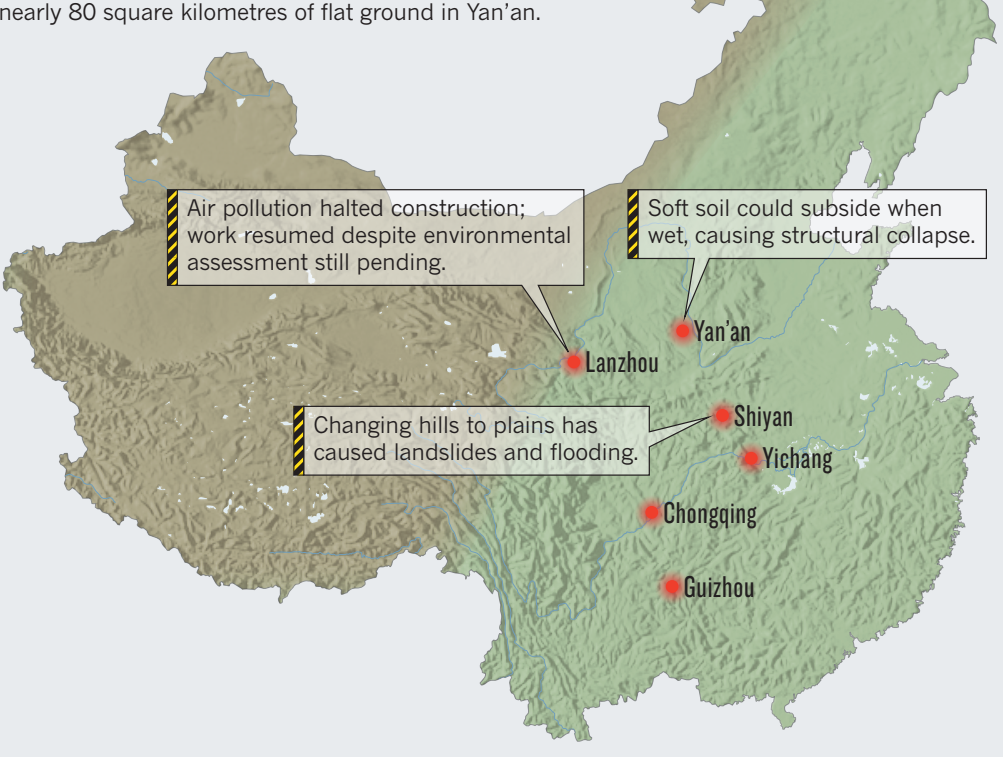

This increases the risk of soil erosion and groundwater loss, because farmlands and forests block wind and retain moisture and soil grains. During the earth-moving project in the city of Lanzhou ${ }^{8}$, soil erosion is expected to increase by $10 \%$ and concentrations of dust particles in the air by $49 \%$.

Many land-creation projects in China ignore environmental regulations, because local governments tend to prioritize making money over protecting nature. When air pollution associated with the Lanzhou project became visible in April 2013, work was halted pending an environmental assessment. Four weeks later, construction resumed because of mounting costs to the local government and contractors. The assessment has yet to be completed.

The assumption that land creation always brings economic benefits needs to be challenged through cost modelling. For example, the 100-billion-renminbi (US\$16-billion) total cost over ten years of the Yan'an plan could take decades to recoup. The infill area cannot be built on for at least another decade, when its ground base becomes stable. This long payback period will dissuade some investors from buying the land, thus increasing economic risk.

\section{INADEQUATE INSIGHT}

Research into land creation is insufficient. A lack of expertise, collaboration and funding means that scientists have not been able to conquer technical problems or provide tested, efficient or timely support for the engineering projects. Basic research into the hydraulic parameters of soils and aquifers was stalled by a year-long delay in distributing government research funding for 2013.
Research is local and narrow. In Yan'an, the Chinese government has granted 30 million renminbi to several local institutes and universities to solve some technical problems. The research focuses on the monitoring and modelling of ground deformation, subsidence, hydrogeological changes and protection of the surrounding slopes. Economics and environmental risks are not included.

The number and breadth of research teams is inadequate, and the limited experience and skills of local scientists are a problem. Researchers in Yan'an, for example, have expertise in hydrogeology and engineering geology but are less experienced in soilwater research, which is important for the stability of the ground base. Institutes have struggled to collaborate. Each manages its own sub-project and seldom shares research data with others. Teams must repeat work to obtain data that another institute already has, wasting time and money.

No international organizations or scientists who have rich expertise and practical experience are participating. Those who have participated in mountaintop removal in the United States should be invited to take part in Chinese projects.

Research funding comes exclusively from the government. Industries, institutes and universities carry out the research, yet few governmental departments are involved, limiting their influence. In Yan'an, only the Shaanxi Science and Technology Department and the Chinese Ministry of Science and Technology have participated or provided funding. Other local government departments involved in areas such as housing or environmental 

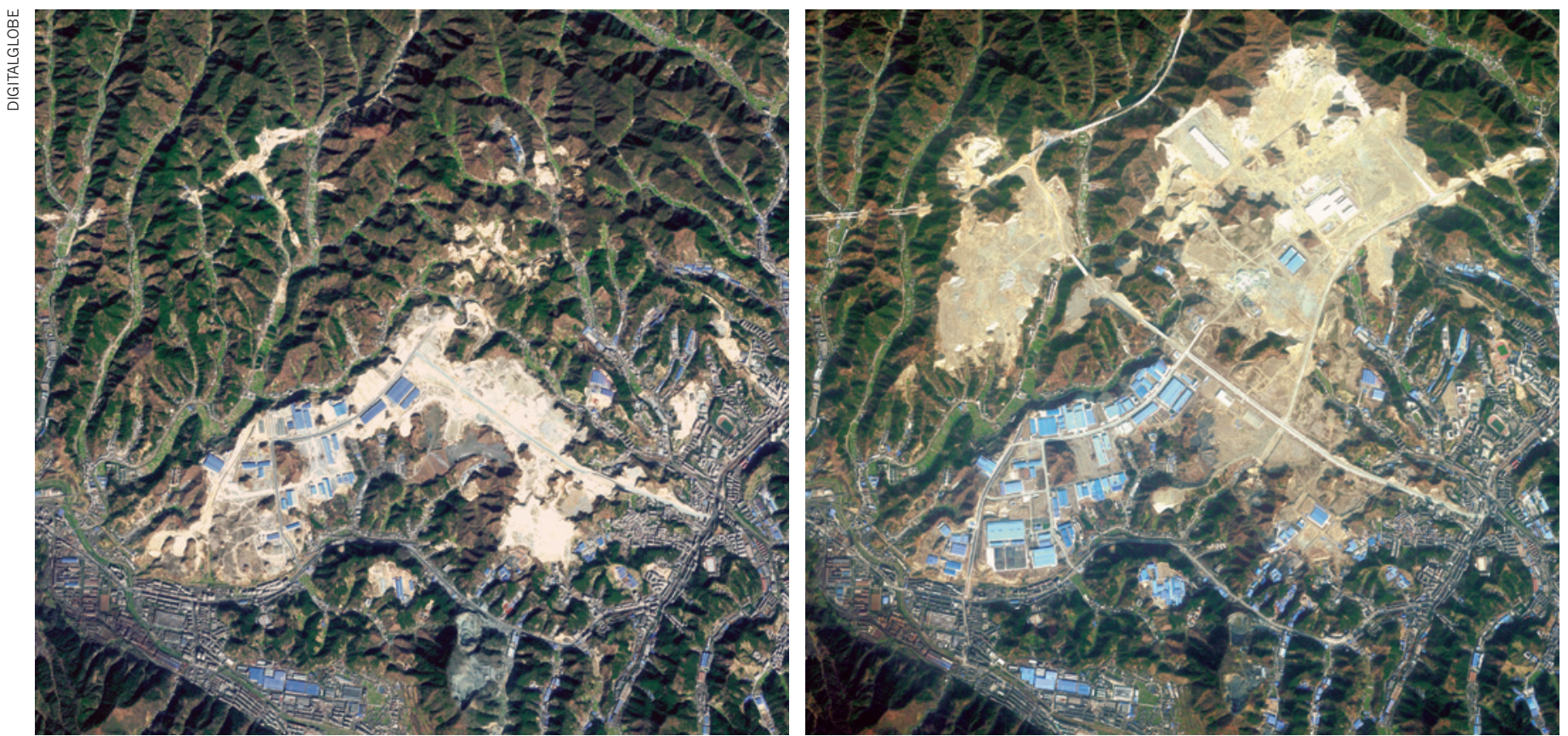

Satellite images of western Shiyan, China, in 2010 (left) and 2012 (right) after several peaks have been flattened.

protection are not involved.

Government funds are not allocated according to scientific significance or need. Rather, they are directed on discretion of the local institute in charge of the project. For instance, water-soil interaction is the key factor affecting the success of the Yanan project but the drive to understand it attracts only $12 \%$ of the research budget. And environmental and ecology-related research receives no funding in Yanan, despite being very much in the public interest.

Research also lags behind the engineering work, and so has little impact. In Yan'an, the research started three months after excavations began. Lab tests that could have established the exact moisture content needed to harden loess foundations were unavailable to guide the project. Preliminary results are now available, but for only a few soils. An earlier start could have delivered more.

\section{BOOST RESEARCH}

We call on the Chinese government to accelerate research efforts urgently. With good guidance, land creation could proceed with fewer risks and more benefits.

China's best researchers from Beijing, Shanghai and Wuhan should join regional collaborations. And a national network, similar to the National Basic Research Programs of China, should be established to coordinate this effort, to ensure quality and avoid duplication.

Scientists from the US Geological Survey, the US Environmental Protection Agency, the International Association of Hydrogeologists and universities in Canada, the United States and Europe should also be brought in. Local construction industries could be involved and provide funds and equipment.

Local and national governments should allocate funds according to scientific importance, guided by of a pool of national experts including hydrogeologists, environmentalists, economists and government officials. Extra funding must be found for environmental and ecological risk assessment and for economic studies of land creation. An independent management organization should be established and supervised by local government to manage and share the research data.

Environmentalists, ecologists, hydrogeologists, engineers and decision-makers must collaborate to find solutions to

\section{"Fconomists environmental prob-} need to assess disappearances of the costs and small creeks, endanbenefits of gering of wild aniland-creation mals and birds and projects." altered groundwater flows.

As a minimum the following recommendations should be heeded: during earth movement, soils should be watered to raise the moisture content to avoid dust pollution; ground cover and trees on hills and in gullies that are destroyed before infilling should be replanted as soon as possible to prevent soil erosion; and farmers who lose farmland should be compensated.

Economists need to assess the costs and benefits of land-creation projects and suggest ways to reduce the risks before these projects begin. Where high economic risks and low profitability are predicted, projects should not proceed even if they are technically feasible, at least for now. Where there is no profit, governments should be dissuaded from going ahead.

Consulting environmental scientists and economists in advance will prevent or minimize extra costs arising from delays or troubleshooting. Pausing the Yan'an excavations would cost 500,000 renminbi a day in payments to idle construction workers, for instance?.

As in the ancient fable, China is moving mountains. Until we know more about the consequences, we urge governments to seek scientific advice and proceed with caution.

Peiyue Li is assistant professor of hydrogeology and environmental science in the School of Environmental Science and Engineering at Chang'an University, China. Hui Qian and Jianhua Wu are in the School of Environmental Science and Engineering at Chang'an University, China. e-mail:lipy2@163.com

1. Allen, F., Qian, J. \& Qian, M. J. Finan. Econ. 77, 57-116 (2005).

2. Li, M. in The Population of Modern China (eds Poston, D. L. Jr \& Yaukey, D.) 83-112 (Springer, 1992).

3. Qian, W. China Newsweek 2, 26-29 (2013; in Chinese).

4. Sun, J. Z. Loessology Vol. 1 (Hong Kong Archaeological Society, 2005).

5. Song, Q. China Construction 20, 21-23 (2013; in Chinese).

6. Burns, S. S. Bringing Down the Mountains: The Impact of Mountaintop Removal Surface Coal Mining on Southern West Virginia Communities (West Virginia Univ. Press, 2007).

7. Crotty, M. G. Villanova Environ. Law J. 13, 287-313 (2002).

8. Zhang, M. Q., Ji, S. N. \& Sun, N. X. J. Arid Land Res. Environ. 23, 77-81 (2009; in Chinese).

9. Zhao, F. China Bus. J. A13, 1-5 (2013; in Chinese). 